Check for updates

Cite this: RSC Adv., 2019, 9, 35887

Received 30th August 2019

Accepted 28th October 2019

DOI: $10.1039 / c 9 r a 06893 g$

rsc.li/rsc-advances

\section{Seed-mediated synthesis of Au@PtCu nanostars with rich twin defects as efficient and stable electrocatalysts for methanol oxidation reaction $\dagger$}

\author{
Ting Bian, ${ }^{\text {ad }}$ Biao Sun, ${ }^{a}$ Sai Luo, (D) ${ }^{\mathrm{c}}$ Long Huang, ${ }^{\text {a }}$ Shan Su, ${ }^{\mathrm{b}}$ Chunfeng Meng, ${ }^{\mathrm{d}}$ \\ Shichuan Su, ae Aihua Yuan (DD *b and Hui Zhang (DD *c
}

Pt-based nanocrystals with a twinned structure are highly desirable to achieve high performances in both catalytic activity and durability for methanol oxidation reaction (MOR). However, it still remains great challenge for producing such twinned nanocrystals due to the high internal strain energy of Pt. Here we present a seed-mediated approach to generate Au@PtCu nanostars with a five-fold twinned structure using Au decahedra as seeds. The composition of $\mathrm{Pt} / \mathrm{Cu}$ in the nanocrystals was tuned by varying the molar ratio of $\mathrm{Pt}$ to $\mathrm{Cu}$ salt precursors with the amount of $\mathrm{Au}$ seeds being the same. Through composition optimization, Au@ $\mathrm{Pt}_{1.2} \mathrm{Cu}$ nanostars achieved the highest specific $\left.(1.06 \mathrm{~mA} \mathrm{~cm})^{-2}\right)$ and mass (0.18 mA mg ${ }_{\mathrm{Pt}}{ }^{-1}$ ) activities for MOR, which were about 5.9 and 1.6 times higher than those of commercial Pt/C, respectively. After accelerated stability test (ADT) for 1500 cycles, such nanostars remained $\sim 95 \%$ of specific activity compared to a loss of $\sim 28 \%$ for commercial $\mathrm{Pt} / \mathrm{C}$, indicting their superior durability for MOR. We believed that this enhancement may arise from the unique twinned structure and possible synergetic effect between Pt and Cu components.

\section{Introduction}

Renewable and clean energy has recently attracted much attention owing to the increasing demand for lowering our dependence on fossil fuels. ${ }^{1-3}$ Direct methanol fuel cells (DMFC) are considered as promising green energy conversion devices due to their high efficiency, high energy density and convenient storage of liquid fuel. ${ }^{4,5}$ In spite of many attempts in the last decade to design and fabricate non-Pt catalysts for methanol oxidation reaction (MOR) at the anode, $\mathrm{Pt}$ still remains the choice of preferred catalyst for DMFC. ${ }^{6}$ However, the high cost, limited abundance and severe poisoning effect from CO have been the key obstacles of Pt for the extensive use in DMFC. ${ }^{7}$ To alleviate these problems, it is highly urgent to develop new types

${ }^{a}$ School of Energy and Power Engineering, Jiangsu University of Science and Technology, Zhenjiang 212003, People's Republic of China

${ }^{b}$ School of Environmental and Chemical Engineering, Jiangsu University of Science and Technology, Zhenjiang 212003, People's Republic of China. E-mail: aihua.yuan@just. edu.cn

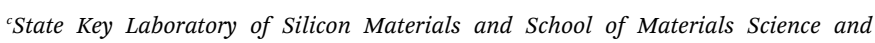
Engineering, Zhejiang University, Hangzhou 310027, People's Republic of China. E-mail: msezhanghui@zju.edu.cn

${ }^{d}$ School of Materials Science and Engineering, Jiangsu University of Science and Technology, Zhenjiang 212003, People's Republic of China

${ }^{e}$ Zhenjiang Key Laboratory of Marine Power Equipment Performance, Zhenjiang 212003, People's Republic of China

$\dagger$ Electronic supplementary information (ESI) available. See DOI: 10.1039/c9ra06893g of Pt-based nanocrystals with intriguing catalytic performance and high utilization efficiency of Pt atoms. One of the appealing approaches to improve the catalytic activity toward MOR is incorporating non-noble metal into Pt nanocrystals to construct bimetallic alloys. Some pioneer works have demonstrated that the improved activity of bimetallic electrocatalysts can be ascribed to electronic effect and/or bi-functional mechanism arising from the interaction between each component in the alloy. ${ }^{8-10}$ Among various Pt-based electrocatalysts, $\mathrm{PtCu}$ nanocrystals have been regarded as a promising candidate due to their relatively low cost, excellent catalytic activity, and super anti-CO poisoning capability. ${ }^{\mathbf{1 1 , 1 2}}$

Apart from chemical composition, morphology also has a strong influence on the electrocatalytic activity caused by the difference in the arrangement of surface atoms (geometric effect). ${ }^{13}$ Accordingly, significant progress has been made in the synthesis of PtCu alloyed nanocrystals with well-defined shapes, such as cube, ${ }^{\mathbf{1 4}}$ octahedron, ${ }^{15}$ nanocage, ${ }^{16}$ nanowire ${ }^{17}$ and nanosheet. ${ }^{18}$ In addition, Pt-based alloys with rich defects are expected to induce positive effects on electrocatalytic reactions relative to their perfect counterparts due to the modification of surface reactivity and electronic structure. ${ }^{19,20}$ It is generally known that there are three different types of defects, including point defect, linear defect, and planar defect. As a kind of typical surface defects, twin structure has attracted much attention. ${ }^{21}$ For example, Sun and co-workers have recently demonstrated that the specific activity of the icosahedral $\mathrm{Pt}_{3} \mathrm{Cu}$ catalysts for MOR was 1.31 times higher than that of the octahedral $\mathrm{Pt}_{3} \mathrm{Cu}$ 
catalysts, even though with the same exposed $\{111\}$ facets and composition. ${ }^{22}$ Similarly, the electrocatalytic activity of the fivefold-twinned $\mathrm{PtCu}$ nanoframes for MOR were highly evaluated. ${ }^{23}$ However, in such designs, the twinned structure is easily corroded under harsh operating conditions, which prevents the further application of twin defects in optimizing catalytic performance.

Core-shell structures are a class of nanostructured materials that have received increased attention owing to their fantastic properties. On the one hand, the electronic coupling between core and shell is advantageous for achieving high catalytic performances. ${ }^{24,25}$ On the other hand, by sophisticated selecting of the seeds with well-defined shapes, seeded growth method has emerged as a powerful tool for shape-controlled synthesis of core-shell nanocrystals. ${ }^{26,27}$ As demonstrated in our previous work, small size Au particle tends to assume a multiply twinned structure (e.g., <10 nm), which is an appropriate core material for establishing Pt-based catalysts with twin configurations. ${ }^{28}$ Moreover, it has been found that the addition of Au effectively increases the dissolution potential of Pt layer as a result of preventing Pt-based catalysts from degradation. ${ }^{29,30}$ Sun and coworkers demonstrated an oil-phase method for the synthesis of $\mathrm{Au} / \mathrm{CuPt}$ core-shell nanoparticles, showing enhanced catalytic activity and duality for MOR. ${ }^{31}$ However, it still remains a challenge to precise control of the growth of PtCu alloys on twinned $\mathrm{Au}$ cores to form multimetallic core-shell nanocrystals with well-defined shapes and rich defects on surface.

Herein, we report a seed-mediated approach to synthesize $\mathrm{Au} @ \mathrm{PtCu}$ nanostars with rich twin defects as a new kind of high-performance electrocatalysts. Impressively, the Au@PtCu nanostars exhibited better electrocatalytic properties in terms of activity and stability toward MOR relative to commercial Pt/C, $\mathrm{Au} @ \mathrm{PtCu}$ decahedra, Au@Pt nanoparticles (NPs), PtCu alloyed nanobranches under acid conditions due to the unique twin structure and synergetic effect between $\mathrm{Pt}$ and $\mathrm{Cu}$.

\section{Experimental}

\subsection{Chemicals and materials}

Chloroauric acid tetrahydrate $\left(\mathrm{HAuCl}_{4} \cdot 4 \mathrm{H}_{2} \mathrm{O}, 99.9 \%\right)$, hexadecyltrimethyl ammonium bromide (CTAB, 99\%), ammonium bromide $\left(\mathrm{NH}_{4} \mathrm{Br}, \mathrm{AR}\right)$, ethanol $\left(\mathrm{C}_{2} \mathrm{H}_{5} \mathrm{OH}, \mathrm{AR}\right)$, Trichloromethane $\left(\mathrm{CHCl}_{3}, 99 \%\right)$, and cyclohexane $\left(\mathrm{C}_{6} \mathrm{H}_{12}, \mathrm{AR}\right)$ were purchased from Sinopharm Chemical Reagent Co., Ltd. Oleylamine (OAm, 80-90\%), chloroplatinic acid hexahydrate $\left(\mathrm{H}_{2} \mathrm{PtCl}_{6} \cdot 6 \mathrm{H}_{2} \mathrm{O}\right.$, $99.9 \%)$, cupric nitrate trihydrate $\left(\mathrm{Cu}\left(\mathrm{NO}_{3}\right)_{2} \cdot 3 \mathrm{H}_{2} \mathrm{O}, 99.99 \%\right)$, tertbutylamine $\left(\mathrm{C}_{4} \mathrm{H}_{11} \mathrm{~N}, 99 \%\right)$ and perchloric acid $\left(\mathrm{HClO}_{4}\right.$, 99.999\%) were purchased from Aladdin. Methanol $\left(\mathrm{CH}_{3} \mathrm{OH}\right.$, 99.9\%) and Nafion (5 wt\%) were purchased from Sigma-Aldrich. All the chemicals and materials were all used as received.

\subsection{Synthesis of Au decahedral seeds}

In a typical synthesis, $7 \mathrm{~mL}$ of OAm was preheated at $180{ }^{\circ} \mathrm{C}$ for $10 \mathrm{~min}$ in air under magnetic stirring. $3 \mathrm{~mL}$ of an OAm solution containing $12.4 \mathrm{mg}$ of $\mathrm{HAuCl}_{4}$ was injected quickly, which was then kept at $180^{\circ} \mathrm{C}$ for additional $3 \mathrm{~h}$. The product was collected by centrifugation, washed with ethanol and hexane for three times, and then re-dispersed in $10 \mathrm{~mL}$ of OAm for further use.

\subsection{Synthesis of Au@PtCu nanostars}

In a standard preparation, $2 \mathrm{~mL}$ of $\mathrm{Au}$ seeds and $4 \mathrm{~mL}$ of OAm solution containing $300 \mathrm{mg}$ CTAB were added to a $25 \mathrm{~mL}$ threenecked flask. Subsequently, $4 \mathrm{~mL}$ of OAm solution containing $\mathrm{H}_{2} \mathrm{PtCl}_{6}(0.02 \mathrm{mmol})$ and $\mathrm{Cu}\left(\mathrm{NO}_{3}\right)_{2}(0.06 \mathrm{mmol})$ were injected. After that, the reaction was heated at $240{ }^{\circ} \mathrm{C}$ in nitrogen under magnetic stirring for $3 \mathrm{~h}$. The solution was centrifuged and washed three times with ethanol and hexane to remove CTAB and OAm for further applications. We also systematically investigated the effects of various parameters, including reaction time, composition, amounts of CTAB, as well as temperature, on the morphology of resultant products.

\subsection{Synthesis of $\mathrm{Au@Pt}{ }_{3}$ NPs and PtCu alloy nanobranches}

The Au@Pt ${ }_{3}$ NPs and PtCu alloy nanobranches were generated using the aforementioned standard procedure without adding $\mathrm{Cu}$ precursors or $\mathrm{Au}$ seeds, respectively.

\subsection{Preparation of carbon-supported catalysts}

In a standard preparation, carbon black particles were dispersed in chloroform and sonicated for $30 \mathrm{~min}$. The as prepared Au@ $\mathrm{Pt}_{1.2} \mathrm{Cu}$ nanostars, $\mathrm{Au} @ \mathrm{Pt}_{3.2} \mathrm{Cu}$ decahedra, $\mathrm{Au} @ \mathrm{Pt}_{3} \mathrm{NPs}$, and $\mathrm{Pt}_{1.2} \mathrm{Cu}$ nanobranches were added to this dispersion at the mass ratio (nanocrystals-to-carbon-black) of $20: 80$. This mixture was further sonicated for $10 \mathrm{~min}$ and stirred overnight. After that, the products were collected by centrifugation and re-dispersed in tert-butylamine at a concentration of $0.5 \mathrm{mg}$-nanocrystals $\mathrm{mL}^{-1}$. The mixture was kept under magnetic stirring for 3 days and then centrifuged and washed three times with ethanol.

\subsection{Morphological, structural, and elemental characterizations}

Morphology and elemental distributions of the samples were analyzed using transmission electron microscope (TEM, Hitachi HT-7700, $100 \mathrm{kV}$ ), high-resolution TEM (HRTEM, Tecnai G2 F20, $200 \mathrm{kV}$ ), and high-angle annular dark-field scanning TEM equipped with a super energy dispersive X-ray (EDX) spectroscope (HAADF-STEM, Titan G2 80-200, $200 \mathrm{kV}$ ). The atomic ratio of $\mathrm{Au}, \mathrm{Pt}$ and $\mathrm{Cu}$ in the samples was determined by using inductively coupled plasma atomic emission spectrometry (ICPAES, IRIS Intrepid II XSP, TJA Co., USA). X-ray powder diffraction (XRD) patterns were recorded by Shimadzu XRD-6000 diffractometer (Cu- $\mathrm{K}_{\alpha}$ radiation). X-Ray Photoelectron Spectrometer (XPS) was performed on ESCALAB 250Xi (Thermo UK). Thermogravimetric analysis (TGA) was carried out on a thermogravimetric analyzer (Pyris Diamond TG-DTA) from room temperature to $800{ }^{\circ} \mathrm{C}$ at a heating rate of $10{ }^{\circ} \mathrm{C} \mathrm{min}^{-1}$.

\subsection{Electrochemical measurements}

The electrochemical measurements were performed at a rotating disk electrode (RDE, Pine Research Instrumentation, 
United States) connected to an electrochemical workstation (CHI 760E). A conventional three-electrode system was adopted with a glassy carbon electrode (GCE, $0.5 \mathrm{~mm}$ in diameter) as the working electrode, a platinum wire as the auxiliary electrode, and a silver chloride electrode $(\mathrm{Ag} / \mathrm{AgCl})$ as the reference electrode, respectively. $5 \mathrm{mg}$ of the as-prepared $\mathrm{Au} @ \mathrm{Pt}_{1.2} \mathrm{Cu} / \mathrm{C}$, $\mathrm{Au} @ \mathrm{Pt}_{3.2} \mathrm{Cu} / \mathrm{C}, \mathrm{Au} @ \mathrm{Pt}_{3} / \mathrm{C}, \mathrm{Pt}_{1.2} \mathrm{Cu} / \mathrm{C}$, and commercial $\mathrm{Pt} / \mathrm{C}$ catalysts were dispersed in $1 \mathrm{~mL}$ of a mixed solvent containing water, isopropanol and Nafion (5\%) at the volumetric ratio of $1: 1: 0.025$. Thereafter, $10 \mu \mathrm{L}$ of the catalyst ink was added onto the GCE to make the modified working electrode. Cyclic voltammograms (CVs) were recorded in a $\mathrm{N}_{2}$-saturated $0.1 \mathrm{M}$ $\mathrm{HClO}_{4}$ and/or $0.1 \mathrm{M} \mathrm{HClO}_{4}+1 \mathrm{M} \mathrm{CH}_{3} \mathrm{OH}$ solution with a scan rate of $50 \mathrm{mV} \mathrm{s}^{-1}$. The accelerated stability test (ADT) was carried out at a scan rate of $100 \mathrm{mV} \mathrm{s}^{-1}$ for 1500 cycles in $\mathrm{N}_{2^{-}}$ saturated $0.1 \mathrm{M} \mathrm{HClO}_{4}+1 \mathrm{M} \mathrm{CH} \mathrm{CH}_{3} \mathrm{OH}$ solution. The chronoamperometry curves were obtained at $0.6 \mathrm{~V}$ for $10000 \mathrm{~s}$.

\section{Results and discussion}

\subsection{Characterization of the prepared Au@PtCu nanostars}

The five-fold twinned $\mathrm{Au} @ \mathrm{PtCu}$ core-shell nanostars were prepared by simultaneous reduction of $\mathrm{H}_{2} \mathrm{PtCl}_{6}$ and $\mathrm{Cu}\left(\mathrm{NO}_{3}\right)_{2}$ in oleylamine (OAm) containing cetyltrimethylammonium bromide (CTAB) with Au decahedra as the seeds. Representative transmission electron microscopy (TEM) image (Fig. S1a†) shows that the $\mathrm{Au}$ seeds were highly uniform with an average size of $c a .8 \mathrm{~nm}$. From high-resolution TEM (HRTEM) image (Fig. S1b $\dagger$ ), apparent five-fold twins were clearly observed from the center of a nanocrystal, which was generally recognized as decahedral nuclei. Fig. 1 shows the morphological, structural, compositional characterizations of $\mathrm{Au} @ \mathrm{PtCu}$ nanostars that prepared using the standard procedure with the molar ratio of $\mathrm{Pt}$ and $\mathrm{Cu}$ salt precursors being 1 : 3. From TEM image (Fig. 1a), most of the nanocrystals were star-shaped with an approximate size of $26.7 \pm 2.5 \mathrm{~nm}$. The size was defined as the diameter of the circumscribed circle projected by the pentagram, as shown in Fig. S2. $\dagger$ In addition, HRTEM image clearly indicates five-fold twins existed in the $\mathrm{Au} @ \mathrm{PtCu}$ nanostars with rich defects (Fig. 1b). The marked fringes with a lattice spacing of $2.25 \AA$ correspond well to $\{111\}$ plane of face-centered cubic (fcc) $\mathrm{PtCu}$, confirming the epitaxy of highly crystalline $\mathrm{PtCu}$ layers on $\mathrm{Au}$ seeds. Energy dispersive X-ray (EDX) mapping images of an individual Au@PtCu nanostar show that the core region is essentially made by $\mathrm{Au}$ (red color), while the shell is dominated by Pt (blue color) and $\mathrm{Cu}$ (green color), demonstrating a coreshell structure (Fig. 1c). The core-shell structure was further confirmed by line-scan analysis of an Au@PtCu nanostar through the arrow direction (Fig. 1d). Moreover, inductively coupled plasma atomic emission spectrometry (ICP-AES) shows that the atomic ratio of $\mathrm{Au} / \mathrm{Pt} / \mathrm{Cu}$ in the nanostar is $1: 3.27: 2.79$ (labelled as $\mathrm{Au} @ \mathrm{Pt}_{1.2} \mathrm{Cu}$ due to surface chemical formula close to $\mathrm{Pt}_{1.2} \mathrm{Cu}$ ), which is remarkably higher than the molar ratio $\left(n_{\mathrm{Pt}}: n_{\mathrm{Cu}}=1: 3\right)$ between $\mathrm{Pt}$ and $\mathrm{Cu}$ salt precursors fed in the synthesis (see Table $\mathrm{S} 1 \dagger$ ).

$\mathrm{X}$-ray photoelectron spectroscopy (XPS) was used to characterize the electronic state and surface chemistry of $\mathrm{Au}, \mathrm{Pt}$ and $\mathrm{Cu}$ elements in the $\mathrm{Au} @ \mathrm{Pt}_{1.2} \mathrm{Cu}$ nanostars. In $\mathrm{Au} 4 \mathrm{f}$ XPS spectra for $\mathrm{Au} @ \mathrm{Pt}_{3} \mathrm{NPs}$, two peaks at $84.08 \mathrm{eV}\left(\mathrm{Au} 4 \mathrm{f}_{7 / 2}\right)$ and $87.75 \mathrm{eV}(\mathrm{Au}$ $4 f_{5 / 2}$ ) could be assigned to zerovalent state of $\mathrm{Au}^{0}$ (Fig. S3a $\dagger$ ). Impressively, the above pair peaks in $\mathrm{Au} @ \mathrm{Pt}_{1.2} \mathrm{Cu}$ nanostars shift to 83.88 and $87.55 \mathrm{eV}$, respectively (Fig. S4 $\dagger$ ). In the Pt $4 \mathrm{f}$ spectrum of $\mathrm{Au} @ \mathrm{Pt}_{1.2} \mathrm{Cu}$ nanostars, the two strong peaks located at 70.8 and $74.1 \mathrm{eV}$ can be assigned to the $7 / 2$ and $\mathrm{Pt} 4 \mathrm{f}_{5 / 2}$ of metallic $\mathrm{Pt}^{0}$. While, the weak peaks at 71.9 and $75.23 \mathrm{eV}$ are attributed to the bivalent state of Pt(II) (Fig. 2a). Similarly, in Pt 4f XPS spectra for Au@Pt ${ }_{3}$ NPs, two peaks at 71.17 and $74.5 \mathrm{eV}$ could be assigned to $\mathrm{Pt}^{0}$. Besides, the minor peaks assigned to $\mathrm{Pt}^{2+}$ (emerged at 71.97 and $75.3 \mathrm{eV}$ ) (Fig. S3b $\dagger$ ). The Pt $4 \mathrm{f}$ spectra of $\mathrm{Au} @ \mathrm{Pt}_{1.2} \mathrm{Cu}$ nanostars apparently shift to lower binding energies compared with the as-prepared $\mathrm{Au@Pt} \mathrm{t}_{3} \mathrm{NPs}$ due to the alloying with $\mathrm{Cu}$ element. As shown in Fig. $2 \mathrm{~b}$, the $\mathrm{Cu} 2 \mathrm{p}$ spectrum can be split into two groups of peaks associated with metallic $\mathrm{Cu}^{0}$ (931.97 $\mathrm{eV}$ and $951.6 \mathrm{eV}$ ) and bivalent $\mathrm{Cu}(\mathrm{II})$ (935.12 eV and $955.02 \mathrm{eV}$ ). The satellite peak also confirms the presence of a small amount of $\mathrm{Cu}$ (II) in the nanostars. According to the XPS data, the shift of the binding energies provides a strong evidence of the electrons that transfer from $\mathrm{Cu}$ to $\mathrm{Pt}$ and cause a downshift of d-band center of $\mathrm{Pt}$, which is beneficial for improving the MOR properties.

In order to clarify the formation mechanism of the $\mathrm{Au} @ \mathrm{PtCu}$ nanostars, the morphological evolution of the nanocrystals at different reaction time was investigated by TEM analysis (Fig. 3). In the initial stage (Fig. 3a, $t=5 \mathrm{~min}$ ), a large number of nearly spherical nanocrystals were obtained. When the reaction time increased to $30 \mathrm{~min}$ (Fig. 3b), the Au@PtCu nanocrystals presented an irregular polyhedral shape, together with few starshaped nanostructures, implying that $\mathrm{Pt}$ and $\mathrm{Cu}$ atoms were gradually deposited on the Au core. As the reaction proceeded for 60 (Fig. 3c) and 120 min (Fig. 3d), the decahedral Au seeds were encased by PtCu shells with five tiny tips. When the reaction time increased to $180 \mathrm{~min}$, the five-fold $\mathrm{Au@PtCu}$ coreshell nanostars with rich twin defects were formed by preferential epitaxial overgrowth of $\mathrm{PtCu}$ shells on decahedral $\mathrm{Au}$ seeds. Since $\mathrm{Pt}$ and $\mathrm{Cu}$ have a higher surface energy than $\mathrm{Au}$, such overgrowth will increase the total surface energy. ${ }^{32}$ In addition, decahedron is one kind of highly strained structure, consisting of five single-crystalline domains and five twin boundaries. $^{33}$ To release the extra strain energy, most of the Pt and $\mathrm{Cu}$ atoms tend to be deposited at five single-crystalline domains of Au decahedra with only a few atoms being added to five twin boundaries, thereby promoting the formation of star-shaped decahedra.

The composition of Pt and $\mathrm{Cu}$ in the Au@PtCu nanostars was tuned by simply varying the feeding ratio of $\mathrm{Pt}$ to $\mathrm{Cu}$ precursors while keeping the amount of Au seeds constant. On the basis of ICP-AES measurements (see Table $\mathrm{S} 1 \dagger$ ), $\mathrm{Pt}_{3.2} \mathrm{Cu}, \mathrm{Pt}_{2.3} \mathrm{Cu}$, $\mathrm{Pt}_{1.1} \mathrm{Cu}, \mathrm{Pt}_{1.2} \mathrm{Cu}, \mathrm{Pt}_{1.2} \mathrm{Cu}, \mathrm{Pt}_{1.2} \mathrm{Cu}$, and $\mathrm{Pt}_{1.2} \mathrm{Cu}$ alloyed shells were eventually obtained when the molar ratios of $\mathrm{Pt}$ and $\mathrm{Cu}$ precursors varied from $1 / 0.3,1 / 0.6,1 / 1,1 / 2,1 / 3,1 / 4$ to $1 / 5$, respectively. Interestingly, $\mathrm{Cu}$ proportion in the alloyed shell cannot exceed $50 \%$, regardless of the initial amount of $\mathrm{Cu}$ precursor fed in the synthesis, which is in accordance with previous result. ${ }^{34}$ The molar ratios of $\mathrm{Pt}$ to $\mathrm{Cu}$ precursors have 

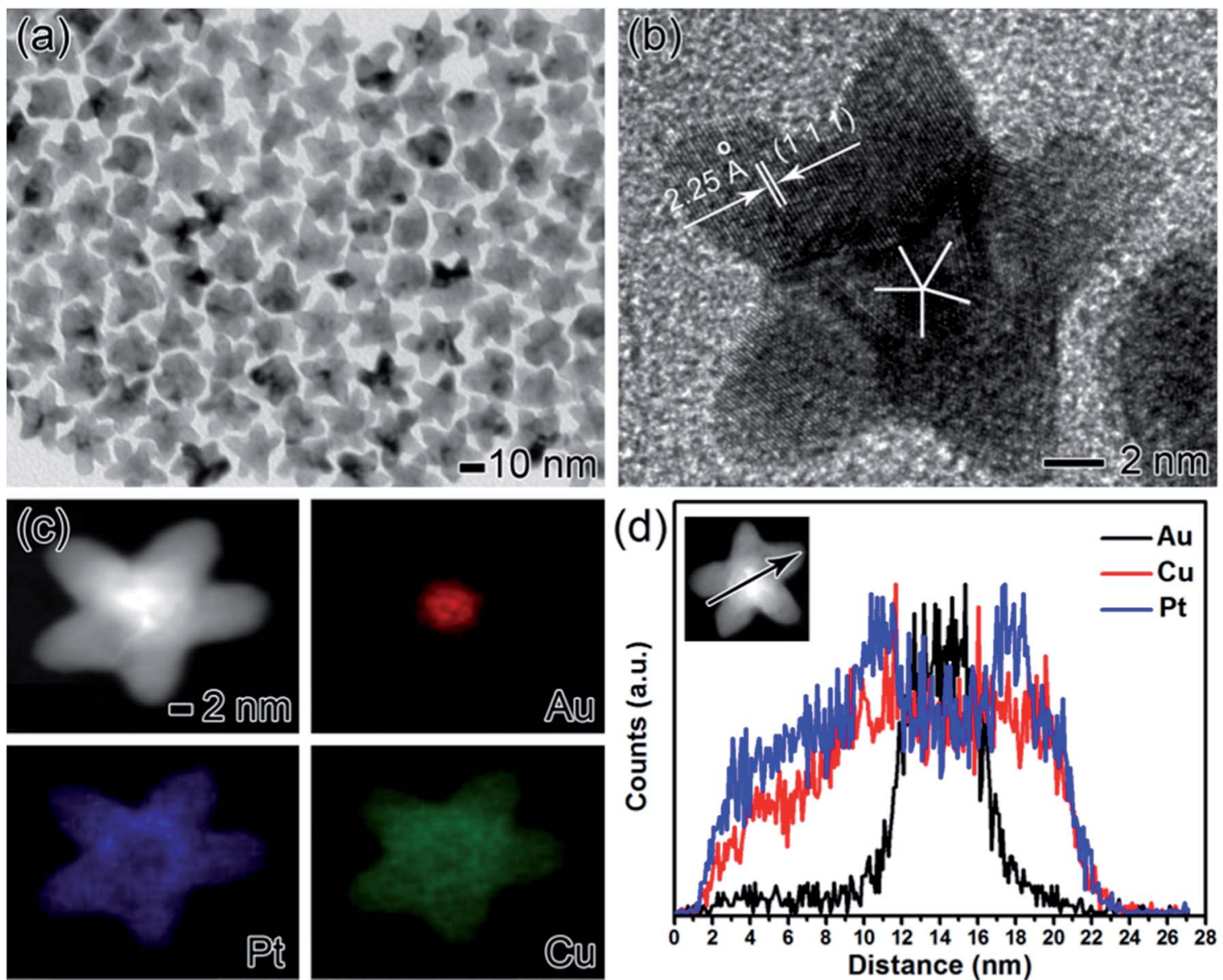

Fig. 1 Morphological, structural, and compositional characterizations of the AuQPtCu nanostars prepared using the standard procedure. (a) TEM image, (b) HRTEM image, (c) HAADF-STEM-EDX image, and (d) EDX line-scan profile.

also an influence on the morphology of the final product, as shown in Fig. S5. $\dagger$ When the molar ratios of $\mathrm{Pt}$ and $\mathrm{Cu}$ precursors were $1 / 0.3$ and $1 / 0.6$, a large number of nearly spherical particles were formed (Fig. S5a and $\mathrm{b} \dagger$ ). As the molar ratios of $\mathrm{Pt}$ and $\mathrm{Cu}$ precursors decreased to $1 / 1$ and $1 / 2$, the nanocrystals with tiny bumps were generated (Fig. S5c and $d \dagger$ ). High-quality star-shaped decahedra were synthesized only when the molar ratio of $\mathrm{Pt}$ and $\mathrm{Cu}$ precursors reached $1 / 3$. Further decreasing such molar ratio to $1 / 5$ promoted the growth of branched arms (Fig. S5e†). Finally, Au@PtCu coreshell nanodendrites were fabricated when the molar ratio of $\mathrm{Pt}$ to $\mathrm{Cu}$ precursors decreased to $1 / 6$ (Fig. S5f $\dagger$ ). In the absence of $\mathrm{Cu}$ precursors or $\mathrm{Au}$ decahedral seeds, $\mathrm{Au} @ \mathrm{Pt}_{3}$ core-shell NPs and $\mathrm{Pt}_{1.2} \mathrm{Cu}$ nanobranches were generated, respectively
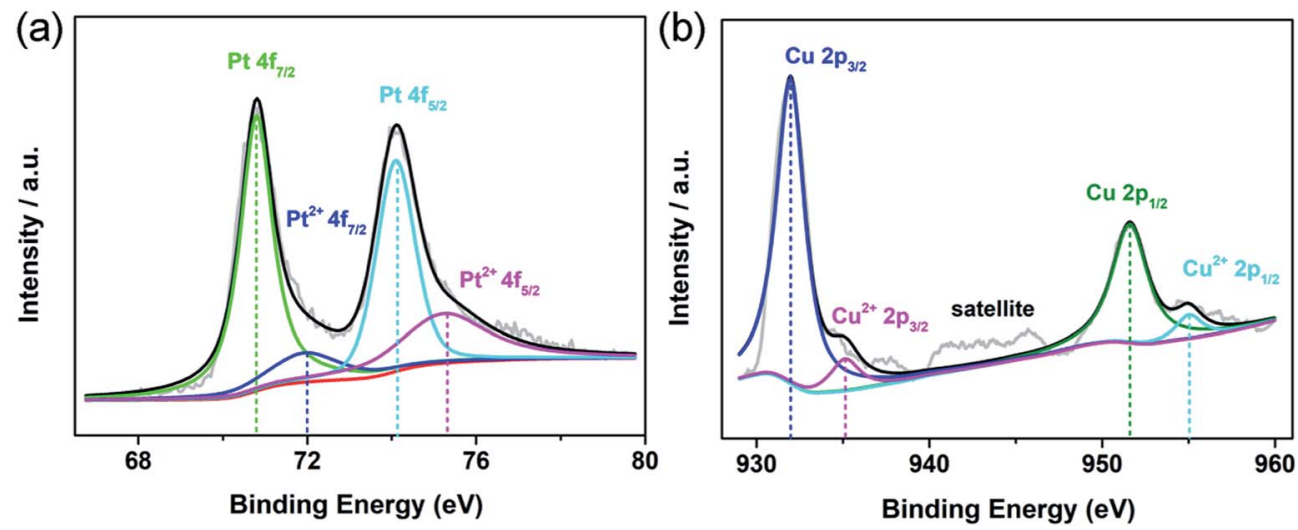

Fig. 2 XPS spectra of the Au@Pt ${ }_{1.2} \mathrm{Cu}$ nanostars for (a) Pt $4 \mathrm{f}$ and (b) $\mathrm{Cu} 2 \mathrm{p}$ orbitals, respectively. 

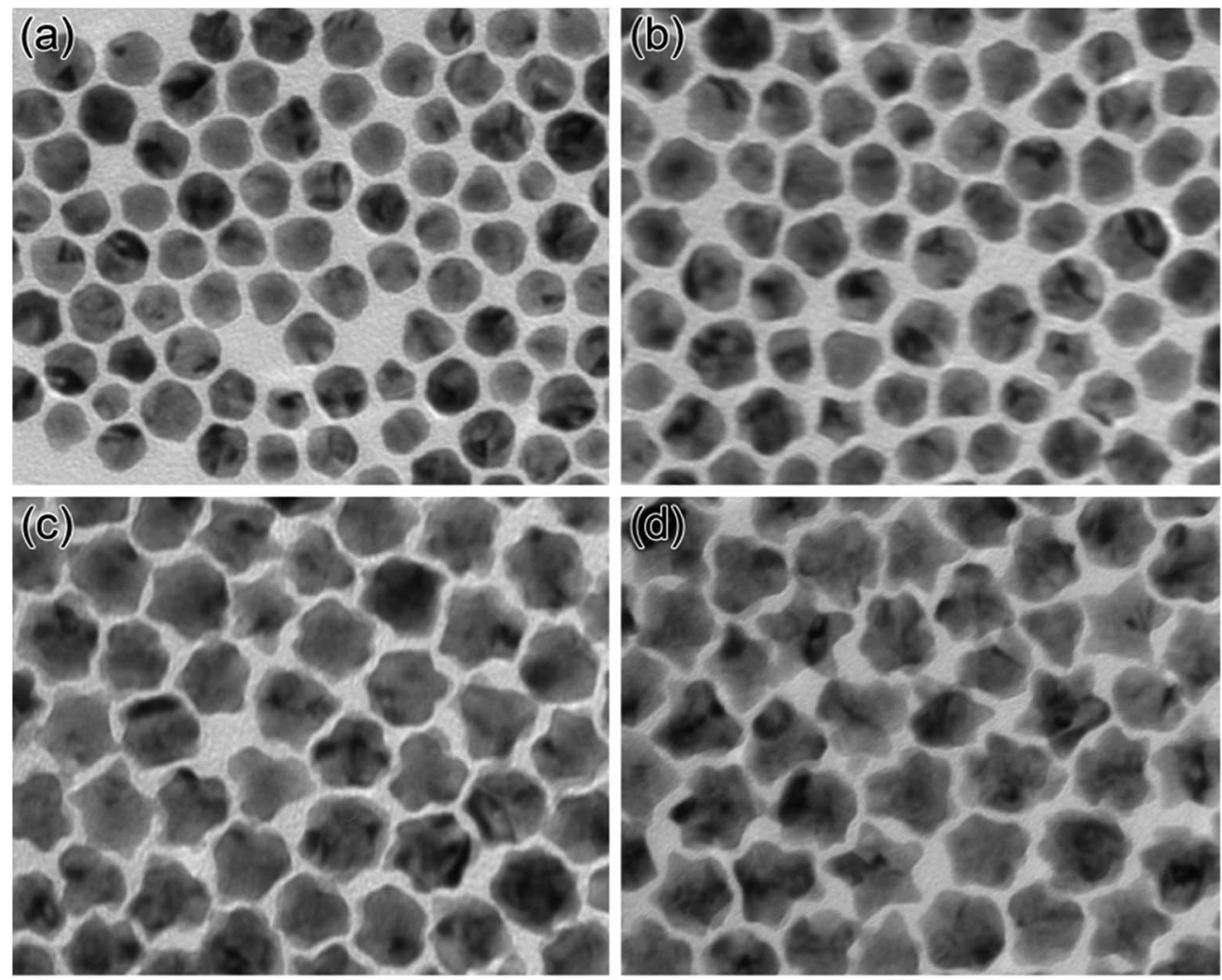

$10 \mathrm{~nm}$

Fig. 3 TEM images of the Au@PtCu nanocrystals prepared using the standard procedure, except for different period of the reactions: (a) 5, (b) 30, (c) 60, and (d) $120 \mathrm{~min}$.

(Fig. S6†). Fig. S7 $\uparrow$ compares X-ray diffraction (XRD) patterns of the $\mathrm{Au} @ \mathrm{Pt}_{1.2} \mathrm{Cu}$ nanostars with $\mathrm{Pt}_{1.2} \mathrm{Cu}$ nanobranches and $\mathrm{Au} @ \mathrm{Pt}_{3}$ NPs. All diffraction peaks of $\mathrm{Pt}_{1.2} \mathrm{Cu}$ nanobranches are located at the position similar to the standard value of $\mathrm{PtCu}$ (JCPDS Card No: 48-1549), indicating the formation of $\mathrm{PtCu}$

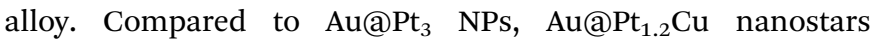
exhibited diffraction peaks with a slight shift to higher angles due to the alloying of $\mathrm{Pt}$ atoms with smaller $\mathrm{Cu}$ atoms. The shift of peaks confirms the lattice shrinkage, which is beneficial to the improvement of electronic structure..$^{35}$

Besides composition, reaction temperature also played a crucial role in controlling the shape of Au@PtCu nanocrystals, as shown in Fig. S7.† At $160{ }^{\circ} \mathrm{C}$, only small rounded nanoparticles less than $10 \mathrm{~nm}$ in size were produced (Fig. S8a $\dagger$ ). In contrast, increasing the temperature to $180{ }^{\circ} \mathrm{C}$ led to the formation of polyhedral nanocrystals. As the temperature further increased to 200 and $220{ }^{\circ} \mathrm{C}$ (Fig. S8c and $\mathrm{d} \dagger$ ), starshaped $\mathrm{Au} @ \mathrm{PtCu}$ decahedra were gradually formed. Highquality nanostars exposed with $\{111\}$ facets were successfully generated only when the reaction temperature exceeded $240^{\circ} \mathrm{C}$. These temperature-dependent experiments further confirmed the growth of $\mathrm{Au} @ \mathrm{PtCu}$ nanostars under a thermodynamic control.

In general, OAm can serve as the solvent, reducing agent, and stabilizer for the synthesis of metal nanocrystals. ${ }^{36}$ For example, amine group in OAm played an important role in facilitating the epitaxial growth of Pt on Au seeds by dramatically decreasing the surface energy of Pt due to the strong adsorption in our previous report. ${ }^{37}$ Moreover, we believe that underpotential deposition (UPD) was responsible for the coreduction of the $\mathrm{Pt}$ and $\mathrm{Cu}$ precursors in OAm. Such a $\mathrm{Cu}$ UPD-assisted mechanism was also observed in our previous studies for the synthesis of the PtCu concave nanocubes. ${ }^{38}$ In addition, $\mathrm{Br}^{-}$ions (derived from $\mathrm{CTAB}$ ) could serve as a capping agent to promote the formation of $\mathrm{Au} @ \mathrm{PtCu}$ nanostars due to their preferential chemisorption on $\{111\}$ surfaces. This result was supported by the control experiments with different amounts of CTAB being added. In the absence of CTAB, uneven polyhedra were obtained, as shown in Fig. S9a. $\dagger$ When the amount of CTAB increased to $100 \mathrm{mg}$ (Fig. S9bi), the nanocrystals with a star-like shape began to appear. Only when the amount of CTAB exceeded $300 \mathrm{mg}$, high-quality nanostars were eventually obtained. The role of $\mathrm{Br}^{-}$ions derived from CTAB can be further confirmed by replacing it with the same amount of ammonium bromide (Fig. S10†).

\subsection{Catalytic activities of Au@PtCu nanostars}

The Au@PtCu nanostars with rich defects were then evaluated as electrocatalysts towards MOR in the acid media. The cyclic voltammograms (CVs) of the $\mathrm{Au} @ \mathrm{Pt}_{1.2} \mathrm{Cu}$ star-shaped and $\mathrm{Au} @ \mathrm{Pt}_{3.2} \mathrm{Cu}$ rounded decahedra were first obtained in $\mathrm{N}_{2^{-}}$ purged $0.1 \mathrm{M} \mathrm{HClO}_{4}$ solutions with the $\mathrm{Au} @ \mathrm{Pt}_{3} \mathrm{NPs}, \mathrm{Pt}_{1.2} \mathrm{Cu}$ 
nanobranches, and commercial $\mathrm{Pt} / \mathrm{C}$ as the references, as shown in Fig. 4a. Their electrochemically active surface areas (ECSAs) were calculated by integrating the charge transfer during the hydrogen adsorption/desorption process, assuming a value of $210 \mu \mathrm{C} \mathrm{cm} \mathrm{cm}^{-2}$ for the adsorption of a hydrogen monolayer. ${ }^{24}$ To be specific, the ECSA of commercial Pt/C was measured to be $63.1 \mathrm{~m}^{2} \mathrm{~g}_{\mathrm{Pt}}{ }^{-1}$, which is significantly higher than those of $\mathrm{Au} @ \mathrm{Pt}_{3.2} \mathrm{Cu}\left(15.3 \mathrm{~m}^{2} \mathrm{~g}_{\mathrm{Pt}}{ }^{-1}\right), \mathrm{Au} @ \mathrm{Pt}_{1.2} \mathrm{Cu}\left(16.8 \mathrm{~m}^{2}\right.$ $\left.\mathrm{g}_{\mathrm{Pt}}{ }^{-1}\right), \mathrm{Au} @ \mathrm{Pt}_{3}\left(46.5 \mathrm{~m}^{2} \mathrm{~g}_{\mathrm{Pt}}{ }^{-1}\right)$, and $\mathrm{Pt}_{1.2} \mathrm{Cu}\left(11.7 \mathrm{~m}^{2} \mathrm{~g}_{\mathrm{Pt}}{ }^{-1}\right)$. The lower ECSA of the Au@PtCu electrocatalysts can be attributed to their large nanoparticle size and the residual organic species (e.g., OAm and CTAB) on their surfaces. Fig. $4 \mathrm{~b}$ and c compares the CV curves of these five electrocatalysts towards MOR that performed in $\mathrm{N}_{2}$-saturated $0.1 \mathrm{M} \mathrm{HClO}_{4}$ solution containing $1 \mathrm{M}$ $\mathrm{CH}_{3} \mathrm{OH}$ at a scan rate of $50 \mathrm{mV} \mathrm{s}^{-1}$. As observed, the specific activities of such electrocatalysts followed a sequence of $\mathrm{Au} @ \mathrm{Pt}_{1.2} \mathrm{Cu}$ nanostars $>\mathrm{Au} @ \mathrm{Pt}_{3.2} \mathrm{Cu}$ decahedra $>\mathrm{Pt}_{1.2} \mathrm{Cu}$

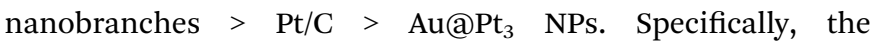
$\mathrm{Au} @ \mathrm{Pt}_{1.2} \mathrm{Cu}$ nanostars achieved the highest specific activity (1.06 $\mathrm{mA} \mathrm{cm}^{-2}$, Fig. 4d) for MOR, which were 2.0, 6.9, 4.0 and 5.9 times higher than those of the $\mathrm{Au} @ \mathrm{Pt}_{3.2} \mathrm{Cu}$ decahedra, $\mathrm{Au} @ \mathrm{Pt}_{3} \mathrm{NPs}, \mathrm{Pt}_{1.2} \mathrm{Cu}$ nanobranches and commercial $\mathrm{Pt} / \mathrm{C}$, respectively. And the mass activities (calculated in $\mathrm{Pt}$ ) of these five catalysts were summarized in Fig. $4 \mathrm{~d}$ and Table $\mathrm{S} 2, \uparrow$ indicating that the $\mathrm{Au} @ \mathrm{Pt}_{1.2} \mathrm{Cu}$ nanostars are the best MOR electrocatalysts. As shown in Fig. $\mathrm{S} 11, \dagger \mathrm{Au} @ \mathrm{Pt}_{1.2} \mathrm{Cu}$ nanobranches achieved lower specific $\left(0.68 \mathrm{~mA} \mathrm{~cm}{ }^{-2}\right)$ and mass $(0.11 \mathrm{~mA}$
$\mathrm{mgPt}^{-1}$ ) activities, indicating that more $\mathrm{PtCu}$ nanobranches on the Au core will hinder the MOR. We think the possible reason is that too much $\mathrm{PtCu}$ dendritic structures will weaken the influence of twins and Au core. Moreover, such a MOR activity for $\mathrm{Au} @ \mathrm{Pt}_{1.2} \mathrm{Cu}$ nanostars was superior to or comparable to those reported for Pt-based MOR electrocatalysts as summarized in Table S3. $\dagger$ In addition, the $I_{\mathrm{f}} / I_{\mathrm{b}}$ ratio, in which $I_{\mathrm{f}}$ and $I_{\mathrm{b}}$ representing the forward and backward current density, respectively, is generally used to evaluate poisoning tolerance of the catalyst to CO. ${ }^{16}$ Compared to the commercial Pt/C (1.2), the $\mathrm{Au} @ \mathrm{Pt}_{1.2} \mathrm{Cu}$ nanostars showed higher $I_{\mathrm{f}} / I_{\mathrm{b}}$ value (2.0), implying better CO tolerance.

To further evaluate the stability of the $\mathrm{Au@} \mathrm{Pt}_{1.2} \mathrm{Cu}$ electrocatalysts toward MOR, CV curves were obtained at a sweep rate of $100 \mathrm{mV} \mathrm{s}^{-1}$ for 1500 cycles with commercial Pt/C as a reference (Fig. 5). As observed, the peak current density of the $\mathrm{Au} @ \mathrm{Pt}_{1.2} \mathrm{Cu}$ nanostars only decreased by $\sim 5 \%$, while a significant loss of $\sim 28 \%$ in current density was obtained for commercial $\mathrm{Pt} / \mathrm{C}$, indicating the superior durability of the $\mathrm{Au} @ \mathrm{Pt}_{1.2} \mathrm{Cu}$ nanostars. The superior catalytic stability of $\mathrm{Au} @ \mathrm{Pt}_{1.2} \mathrm{Cu}$ nanostars was also supported by chronoamperometric measurement (Fig. S12 $\dagger$ ). The current density of $\mathrm{Au} @ \mathrm{Pt}_{1.2} \mathrm{Cu}$ nanostars remained to be $26.5 \mathrm{~mA} \mathrm{mg}^{-1}$ and the $\mathrm{Pt} /$ $\mathrm{C}$ remained $10.2 \mathrm{~mA} \mathrm{mg}^{-1}$, which is about 3 times higher than the $\mathrm{Pt} / \mathrm{C}$. In order to better explain the role of $\mathrm{Au}$ in $\mathrm{Au} @ \mathrm{PtCu}$ nanostars, we compared the decay of current with the stars-like $\mathrm{PtCu} / \mathrm{XC}-72$ reported by Tian et $a .^{39}$ According to the
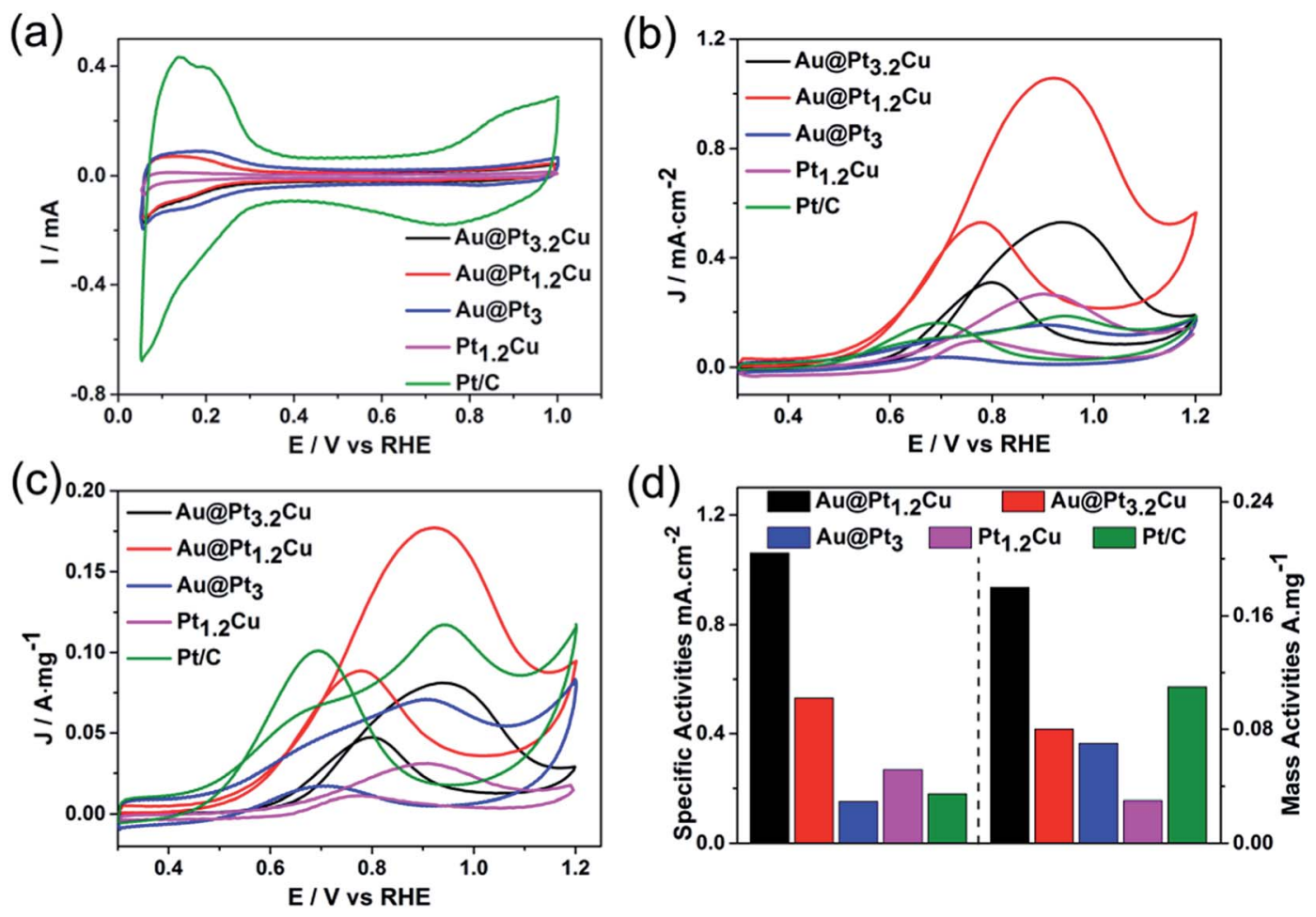

Fig. 4 (a) Cyclic voltammograms (CVs) recorded at room temperature with a sweep rate of $50 \mathrm{mV} \mathrm{s}^{-1}$ in $\mathrm{N}_{2}$-saturated $0.1 \mathrm{M} \mathrm{HClO}_{4}$ for Au@Pt $3.2 \mathrm{Cu}$ decahedra, Au@Pt ${ }_{1.2} \mathrm{Cu}$ nanostars, Au@Pt $\mathrm{NPs}_{3} \mathrm{Pt}_{1.2} \mathrm{Cu}$ nanobranches and commercial Pt/C catalysts. (b and c) CVs of these five catalysts in a $0.1 \mathrm{M} \mathrm{HClO}_{4}+1 \mathrm{M} \mathrm{CH}_{3} \mathrm{OH}$ solution at a scan rate of $50 \mathrm{mV} \mathrm{s}^{-1}$ for MOR normalized by surface area $\left(i_{\mathrm{s}}, \mathrm{mA} \mathrm{cm}{ }^{-2} \mathrm{Pt}_{t}\right)$ and Pt mass $\left(i_{\mathrm{m}}\right.$, $\mathrm{mA} \mu \mathrm{g}_{\mathrm{Pt}}{ }^{-1}$ ), respectively. (d) Specific and mass activities at the peak position of forward curve. 

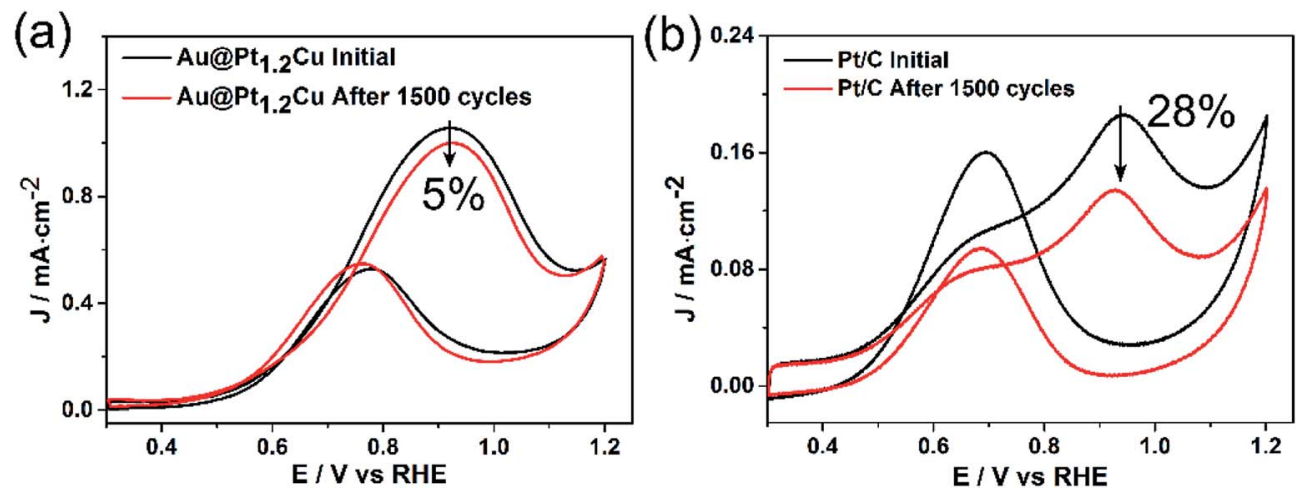

Fig. $5 \mathrm{CVs}$ of the (a) Au@ $\mathrm{PPt}_{1.2} \mathrm{Cu}$ nanostars and (b) commercial Pt/C catalysts before and after 1500 potential cycles between 0.3 and $1.2 \mathrm{~V}$ in a $0.1 \mathrm{M} \mathrm{HClO}_{4}+1 \mathrm{M} \mathrm{CH}_{3} \mathrm{OH}$ solution at a sweep rate of $100 \mathrm{mV} \mathrm{s}^{-1}$.

chronoamperometric curves, the current density of stars-like $\mathrm{PtCu} / \mathrm{XC}-72$ catalysts remained to be $21.1 \mathrm{~mA} \mathrm{mg}^{-1}$ with a loss

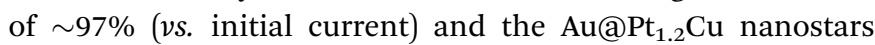
showed a loss of $\sim 82 \%$, indicating that adding an Au core would enhance the stability. Furtherly, the $I_{\mathrm{f}} / I_{\mathrm{b}}$ value of $\mathrm{Au} @ \mathrm{Pt}_{1.2} \mathrm{Cu}$ nanostars is also better than stars-like PtCu. From TEM images in Fig. S13a and b, $\uparrow$ the $\mathrm{Au} @ \mathrm{Pt}_{1.2} \mathrm{Cu}$ nanostars were still welldispersed on the carbon support before and after 1500 cycles $\mathrm{CV}$ tests with part of the $\mathrm{Pt}$ and $\mathrm{Cu}$ atoms being dissolved at five corners of the star-shaped decahedra, which is responsible for a slight drop in MOR properties. There are two possible reasons for improving the electrocatalytic activity of the $\mathrm{Au} @ \mathrm{Pt}_{1.2} \mathrm{Cu}$ nanostars. First, these twinned structures can offer significant benefits toward MOR because they have plenty of defects and $\{111\}$ facets exposed on the surface. ${ }^{28}$ In addition, alloying Pt with $\mathrm{Cu}$ can cause a small compressive strain in the out layer, leading to the modified electronic structure and enhanced activity. Moreover, the $\mathrm{Cu}$ component with an oxophilic feature can facilitate $\mathrm{CO}$ oxidation by catalyzing water to generate hydroxyl species such as $\mathrm{OH}_{\mathrm{ads}}$, and thus enhance the $\mathrm{CO}$ tolerance. ${ }^{40}$ As such, all of these advantages are beneficial for the enhancement in catalytic activity of the $\mathrm{Au} @ \mathrm{PtCu}$ nanostars relative to the commercial Pt/C.

\section{Conclusions}

In summary, high quality five-fold-twinned $\mathrm{Au@PtCu} \mathrm{nanostars}$ with rich defects on the surface were successfully prepared by a seed-mediated approach. With the composition optimization, the $\mathrm{Au} @ \mathrm{Pt}_{1.2} \mathrm{Cu}$ catalysts showed the best electrocatalytic performances toward MOR in an acid electrolyte with specific and mass activities being 5.9 and 1.6 times higher than those of

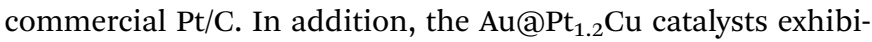
ted excellent durability with a $5 \%$ decay in specific activity after 1500 potential cycling, comparing to a $\sim 28 \%$ loss for commercial Pt/C. This enhancement can be attributed to their unique twinned structure and possible bifunctional mechanism between Pt and $\mathrm{Cu}$ elements. This work provides a facile and effective strategy to synthesize multi-metallic Pt-based catalysts with rich defects for various significant reactions in electrocatalysis.

\section{Conflicts of interest}

There are no conflicts to declare.

\section{Acknowledgements}

We acknowledged financial support by the Natural Science Foundation of Jiangsu (BK20170580), National Science Foundation of China (51901088), China Postdoctoral Science Foundation (2017M611745), Jiangsu Postdoctoral Science Foundation (1701114B), Natural Science Foundation of Jiangsu (17KJB480002), Zhenjiang Key Laboratory of Marine Power Equipment Performance (SS2018006), Postgraduate Foundation (SJCX19_0615). The work on electron microscopy was carried out in the Center of Electron Microscopy and the Analysis Platform of Department of Chemistry, Zhejiang University.

\section{References}

1 X. M. Guo, C. Qian, R. H. Shi, W. Zhang, F. Xu, S. L. Qian, J. Zhang, H. Yang, A. H. Yuan and T. Fan, Small, 2019, 15, 1804855.

2 Y. Li, X. L. Zhong, K. Luo and Z. P Shao, J. Mater. Chem. A, 2019, 7, 15593-15598.

3 L. T. Zhang, Z. L. Cai, Z. D. Yao, L. Ji, Z. Sun, N. H. Yan, B. Zhang, B. B. Xiao, J. Du and X. Q. Zhu, J. Mater. Chem. A, 2019, 7, 5626-5634.

4 Z. Lin, W. Chen, Y. Jiang, T. Bian, H. Zhang, J. Wu, Y. Wang and D. Yang, Nanoscale, 2016, 8, 12812-12818.

5 J. Sheng, J. Kang, H. Ye, J. Xie, B. Zhao, X. Z. Fu, Y. Yu, R. Sun and C. P. Wong, J. Mater. Chem. A, 2018, 6, 3906-3912.

6 H. H. Li, Q. Q. Fu, L. Xu, S. Y. Ma, Y. R. Zheng, X. J. Liu and S. H. Yu, Energy Environ. Sci., 2017, 10, 1751-1756.

7 S. Q. Lu, H. M. Li, J. Y. Sun and Z. B. Zhuang, Nano Res., 2018, 11, 2058-2068. 
8 X. Cui, P. P. Xiao, J. Wang, M. Zhou, W. L. Guo, Y. Yang, Y. He, Z. Wang, Y. Yang and Y. Zhang, Angew. Chem., Int. Ed., 2017, 56, 4488-4493.

9 S. I. Choi, S. Xie, M. Shao, J. H. Odell, N. Lu, H. C. Peng, L. Protsailo, S. Guerrero, J. Park, X. Xia, J. Wang, M. J. Kim and Y. Xia, Nano Lett., 2013, 13, 3420-3425.

10 T. Y. Kwon, M. K. Jun, H. Y. Kim, A. Oh, J. S. Park, H. S. Baik, S. H. Joo and K. Lee, Adv. Funct. Mater., 2018, 28, 1706440.

11 K. Wang, R. R. Sriphathoorat, S. P. Luo, M. Tang, H. Y. Du and P. K. Shen, J. Mater. Chem. A, 2016, 4, 13425-13430.

12 A. X. Yin, X. Q. Min, W. Zhu, W. C. Liu, Y. W. Zhang and C. H. Yan, Chem.-Eur. J., 2012, 18, 777-782.

13 P. Strasser, S. L. Koh, T. L. Anniyev, J. Greeley, K. More, C. F. Yu, Z. Liu, S. Kaya, D. Nordlund and H. Ogasawara, Nat. Chem., 2010, 2, 454-460.

14 D. Xu, S. Y. Bliznakov, Z. P. Liu, J. Y. Fang and N. L. Dimitrov, Angew. Chem., 2010, 122, 1304-1307.

15 T. Bian, H. Liu, B. Sun, B. B. Xiao, Y. Jiang, C. Jin, A. H. Yuan, H. Zhang and D. Yang, J. Alloys Compd., 2019, 788, 13341340.

16 B. Y. Xia, H. B. Wu, X. Wang and X. W. Lou, J. Am. Chem. Soc., 2012, 134, 13934-13937.

17 W. Hong, J. Wang and E. K. Wang, Nano Res., 2015, 8, 23082316.

18 F. S. Saleem, Z. C. Zhang, B. Xu, X. B. Xu, P. L. He and X. Wang, J. Am. Chem. Soc., 2013, 135, 18304-18307.

19 Y. N. Xia, Y. J. Xiong, B. K. Lim and S. E. Skrabalak, Angew. Chem., Int. Ed., 2009, 48, 60-103.

20 J. B. Wu, L. Qi, H. J. You, A. Gross, J. Li and H. Yang, J. Am. Chem. Soc., 2012, 134, 11880-11883.

21 Q. F. Xu, W. L. Chen, Y. C. Yan, Z. M. Wu, Y. Jiang and J. J. Li, Sci. Bull., 2018, 63, 494-501.

22 H. Y. An, N. T. Khi, J. Yoon, H. Lee, H. Baik, J. H. Sohn and K. Lee, Nanoscale, 2015, 7, 8309-8314.

23 X. H. Sun, K. Z. Jiang, N. Zhang, S. J. Guo and X. Huang, ACS Nano, 2015, 9, 7634-7640.

24 Z. C. Zhang, Z. M. Luo, B. Chen, C. Wei, L. Zhao, J. Z. Chen, X. Zhang, Z. Lai, Z. Fan, C. Tan, M. Zhao, Q. Lu, B. Li,
Y. Zong, C. Yan, G. Wang, Z. J. Xu and H. Zhang, Adv. Mater., 2016, 28, 8712-8717.

25 Y. C. Yan, H. Shan, G. Li, F. Xiao, Y. Y. Jiang, Y. Y. Yan, C. Jin, H. Zhang, J. Wu and D. Yang, Nano Lett., 2016, 16, 79998004.

26 M. B. Gawande, A. Goswami, T. Asefa, H. Guo, A. V. Biradar, D. L. Peng, R. Zboril and R. S. Varma, Chem. Soc. Rev., 2015, 44, 7540-7590.

27 Y. L. Xiong, Y. L. Ma, J. J. Li, J. B. Huang, Y. C. Yan, H. Zhang, J. Wu and D. Yang, Nanoscale, 2017, 9, 11077-11084.

28 T. Bian, H. Zhang, Y. Jiang, C. Jin, J. Wu, H. Yang and D. R. Yang, Nano Lett., 2015, 15, 7808-7815.

29 C. Wang, D. Van Der Vliet, K. L. More, N. J. Zaluzec, S. Peng, S. Sun, H. Daimon, G. Wang, J. Greeley and J. Pearson, Nano Lett., 2010, 11, 919-926.

30 J. Zhang, K. Sasaki, E. Sutter and R. Adzic, Science, 2007, 315, 220-222.

31 X. L. Sun, D. G. Li, Y. Ding, W. L. Zhu, S. J. Guo, Z. L. Wang and S. Sun, J. Am. Chem. Soc., 2014, 136, 5745-5749.

32 L. Vitos, A. V. Ruban, H. L. Skriver and J. Kollár, Surf. Sci., 1998, 411, 186-202.

33 Y. Y. Ma, J. Zeng, W. Y. Li, M. McKiernan, Z. X. Xie and Y. N. Xia, Adv. Mater., 2010, 22, 1930-1934.

34 Y. Q. Jiang, Y. Y. Jia, J. W. Zhang, L. Zhang, H. Huang, Z. Xie and L. Zheng, Chem.-Eur. J., 2013, 19, 3119-3124.

35 D. Wang, Y. C. Yu, H. L. Xin, R. Hovden, P. Ercius, J. A. Mundy, H. Chen, J. H. Richard, D. A. Muller and F. J. DiSalvo, Nano Lett., 2012, 12, 5230-5238.

36 Z. C. Xu, C. M. Shen, Y. L. Hou, H. J. Gao and S. H. Sun, Chem. Mater., 2009, 21, 1778-1780.

37 B. H. Wu, N. F Zheng and G. Fu, Chem. Commun., 2011, 47, 1039-1041.

38 Y. Qi, T. Bian, S. I. Choi, Y. Y. Jiang, C. H. Jin, M. S. Fu, H. Zhang and D. Yang, Chem. Commun., 2014, 50, 560-562.

39 D. H. Chen, Y. C. Zhao, X. L. Peng, X. Wang, W. J. Hu, C. Jing, S. S. Tian and J. N. Tian, Electrochim. Acta, 2015, 177, 86-92.

40 Z. L. Liu, X. Y. Ling, X. D. Su and J. Y. Lee, J. Phys. Chem. B, 2004, 108, 8234-8240. 